\title{
The influence of shock during response prevention upon resistance to extinction of an avoidance response
}

\author{
PHILIP J. BERSH \\ Temple Lniversity, Philadelphia, Pennsylvania 19122 \\ and \\ SISTER KATHRYN MILLER \\ Chestnut Hill College, Philadelphia, Pennsylvania 19118
}

\begin{abstract}
A recent study found that avoidance extinction is equally facilitated by response prevention (blocking) whether the latter involves CS-alone or CS-shock presentations. An experiment was performed to determine whether this result was due to the use of a lengthy shock ( 5 sec) during response prevention. Five groups of rats were extinguished: (1) without prior blocking, (2) after blocking with CS only, (3) after blocking with a lengthy (5 sec) CS-contingent shock, (4) after blocking with a brief $(.5 \mathrm{sec})$ CS-contingent shock, or (5) after blocking with a brief $(.5 \mathrm{sec})$ shock only. The group blocked with the brief CS-contingent shock was substantially more resistant to extinction than the other four groups. The unblocked group and the group blocked with brief shock only required more trials to extinguish than the groups blocked with CS only or with lengthy CS-contingent shock, but did not differ from each other. The groups blocked with CS only or with lengthy CS-contingent shock also failed to differ from one another. The data support a significant role for Pavlovian conditioning processes in the effect of response prevention upon avoidance extinction.
\end{abstract}

In a recent paper, Marrazo, Riccio, and Riley (1974) have reported a paradoxical result. They found that prevention of an avoidance response was equally effective in facilitating its extinction whether or not the CS was reinforced by a shock during the response-prevention phase. Reinforced presentations of the CS during response prevention would be expected to enhance, or at least to maintain, its conditioned aversive status. Thus, transfer of control experiments (Trapold \& Overmeier, 1972) have demonstrated that Pavlovian conditioning imparts to the CS excitatory control over an avoidance response even when such conditioning occurs during avoidance-response prevention (e.g., Solomon \& Tumer, 1962). Marrazo et al. interpreted their results to indicate that Pavlovian extinction alone cannot account for the facilitation of avoidance extinction by response prevention. Instead, they suggested that competing responses are acquired during the response-prevention phase even when the CS is reinforced by shock, and that such responses decrease the resistance to extinction of the avoidance response when it can again occur. Other investigators (Bersh \& Keltz, 1971; Coulter, Riccio, \& Page, 1969) have also implicated competing responses (e.g., freezing) in the response-prevention effect. However, Bersh and Keltz still reserved an important role for Pavlovian extinction. Indeed, clear evidence exists for the occurrence of Pavlovian extinction when CS presentations are unreinforced during response prevention (Bersh \& Paynter, 1972). When this fact is combined with the outcome of the investigation by Marrazo et al., the

Reprints may be obtained from Philip $J$, Bersh, Department of Psychology, Temple University, Philadelphia, Pennsylvania 19122. implication is strong that Pavlovian extinction is a by-product of unreinforced CS presentations during response prevention, rather than a contributor to the effect of response prevention upon avoidance extinction.

Before such a conclusion is accepted, however, it is necessary to determine whether the finding that reinforced and unreinforced presentations of the CS during response prevention have the same impact upon avoidance extinction is generally true or depends on special conditions. In this regard, one feature of the procedure employed by Marrazo et al. may be critical. During response-prevention trials for their blocked and shocked group, animals were exposed to shock for $5 \mathrm{sec}$. A shock of this duration might readily suppress all active forms of responding, leaving only the "residual" species-specific defense reaction of freezing or immobility. If this were the case, such behavior would tend to persist when the avoidance response was again possible. With a brief shock, however, freezing might not occur, and the excitatory impact of Pavlovian conditioning upon the CS might reveal itself. The present experiment was undertaken to investigate this possibility. The procedure employed by Marrazo et al. was essentially replicated, but for some groups of blocked and shocked animals, the duration of the shock was reduced to $.5 \mathrm{sec}$ during response-prevention trials.

\section{METHOD}

\footnotetext{
Subjects

Sixty male albino rats of the Sprague-Dawley strain, 250-300 g at the start of the experiment, were assigned to five equal groups and were maintained in individual cages. For a minimum of 5 days, beginning the day following arrival in the laboratory, each animal was handled by the experimenter.
} 
Animals were permitted free access to food and water in their home cages throughout the experiment.

\section{Apparatus}

A Lehigh Valley Electronics shuttlebox, Model 14614, was wired to operate as a one-way avoidance apparatus. Both compartments had a grid floor, but only one side was wired to the LVE scrambler, Model 1311SS, which, in combination with a variable transformer, provided a constant-current shock of $.81 \mathrm{~mA}$. The shock and safe compartments, identical in appearance, were separated by a metal door which could be raised manually by the experimenter. A clear Plexiglas door was inserted during response-prevention trials. The standard stimulus light $\left(7 \frac{1}{2} \mathrm{~W}\right)$ of the shock compartment served as the CS. Except during the CS, the shuttlebox was dark. Entrance into the safe compartment terminated the CS and the shock on escape trials and the CS on avoidance trials.

\section{Procedure}

Acquisition. Each animal was given $2 \mathrm{~min}$ of adaptation to the apparatus with access to both compartments. After this adaptation period, during which the apparatus remained dark and the door was never closed, the animal was placed in the retaining cage. Forty-five seconds later, it was placed in the shock compartment with the door closed. After a variable interval of 2-10 sec, the CS and timer were activated and simultaneously the door was raised. The shock followed $5 \mathrm{sec}$ later. When the animal left the shock compartment, the CS and shock were deactivated, and the experimenter lowered the door. After $45 \mathrm{sec}$ in the safe compartment, the animal was again placed in the shock compartment for the following trial. If the animal left the shock compartment within $5 \mathrm{sec}$ after CS onset, the CS terminated and the shock was avoided. Training continued until the animal reached a criterion of three consecutive avoidance responses. All experimental subjects were then given response-prevention trials, while the Control Group (Group C) was returned to the shock compartment and extinction was begun.

Response prevention. Forty-five seconds after the last acquisition trial, each animal in the four experimental groups was again placed in the shock compartment. During each trial the metal door was raised, while the Plexiglas door remained closed. Forty-five seconds in the retaining cage (ITI) separated response-prevention trials. For three of the experimental groups, a response-prevention trial lasted $5.5 \mathrm{sec}$. Animals in these groups received 15 response-prevention trials rather than 8 as in the experiment of Marrazo et al. (1974) in order to provide a total duration of exposure to the CS equal to that involved in their experiment. The regular blocked group (Group B) was exposed to the CS alone for $5.5 \mathrm{sec}$, while the CS-brief-shock group (Group CS-BS) was shocked during the last $.5 \mathrm{sec}$ of exposure to the 5.5-sec CS. A third group, the brief-shock group (Group BS) received identical trials, but the CS was omitted. Animals of this group were simply shocked for $.5 \mathrm{sec}$ after $5 \mathrm{sec}$ had elapsed since the beginning of each response-prevention trial. Group BS was included to permit assessment of the control over avoidance responding exercised by the CS itself (as opposed to the shock chamber) when a brief shock was made contingent upon the CS. A fourth experimental group, the CS-long-shock group (Group CS-LS) provided a test of whether the critical finding reported by Marrazo et al. would be replicated under the physical arrangements of the present experiment. These animals received eight $10-\mathrm{sec}$ response-prevention trials during which they were shocked for the last $5 \mathrm{sec}$ of exposure to a 10 -sec CS.

Extinction. Forty-five seconds after the last acquisition trial for the control group or after the last response-prevention trial for the experimental groups, extinction began. The animal was
Table 1

Median Number of Trials to Criterion

\begin{tabular}{lrrrrr}
\hline & \multicolumn{5}{c}{ Groups } \\
\cline { 2 - 6 } & C & B & \multicolumn{1}{c}{ BS } & CS-BS & CS-LS \\
\hline Acquisition & 6.0 & 4.5 & 7.0 & 5.5 & 5.5 \\
Extinction & 34.5 & 5.5 & 29.0 & 73.5 & 0 \\
\hline
\end{tabular}

placed in the shock compartment and the door was opened simultaneously with CS onset. Shock was withheld even when the animal failed to leave the shock compartment within the $5-\mathrm{sec}$ avoidance interval. If the animal crossed to the safe compartment within $10 \mathrm{sec}$, the CS terminated and the animal was immediately placed in the retaining cage for $45 \mathrm{sec}$. Failure to cross within $10 \mathrm{sec}$ terminated the trial, and the animal was placed in the retaining cage for the 45-sec ITI. Extinction continued until the animal failed to leave the shock chamber within $10 \mathrm{sec}$ after onset on three consecutive trials.

\section{RESULTS}

Table 1 presents group median numbers of trials to criterion for acquisition and extinction. These medians do not include the criterion trials themselves. Medians were used because of the presence of nonresponding animals in four of the groups. A Kruskal-Wallis $H$ test applied to the acquisition data revealed no significant intergroup differences. On the other hand, group differences in number of trials to the extinction criterion were highly significant $(\mathrm{H}=34.98, \mathrm{df}=4, \mathrm{p}<.001)$. Mann-Whitney $U$ tests were applied to pairwise comparisons between the groups. Group CS-BS was significantly more resistant to extinction than the other four groups (Group CS-BS vs. Group C, $U=31, p=.02$; vs. Group BS, $U=23, p<.01$; vs. Group $B, U=19$, $\mathrm{p}<.002$; vs. Group CS-LS, $U=15, \mathrm{p}<.001$ ). Both Group $C$ and Group BS required significantly more trials to extinguish than Group B (Group C vs. Group B, $\mathrm{U}=9.5, \mathrm{p}<.001$; Group BS vs. Group B, $\mathrm{U}=14.5$, $\mathrm{p}<.001$ ) and Group CS-LS (Group C vs. Group CS-LS, $U=7, p<.001$; Group BS vs. Group CS-LS, $U=12$, $\mathrm{p}<.001)$. The differences between Groups $\mathrm{C}$ and BS and between Groups B and CS-LS were not significant. Parallel results were obtained when comparisons were based on the number of avoidance responses made to a criterion of three consecutive failures to avoid, where an avoidance response is defined as a crossing response with a latency less than $5 \mathrm{sec}$ (the CS-US interval during conditioning).

In each group, except Group $\mathrm{C}$, at least one animal failed to cross at all during extinction (nine in Group CS-LS, five in Group B, two in Group CS-BS, and one in Group BS). These differences in the number of nonresponding animals were significant $\left(\chi^{2}=11.67\right.$, $\mathrm{df}=4, \mathrm{p}=.02$ ). An examination of the group distributions for responding animals only reveals that the distribution for Group CS-BS showed no overlap with 
those for Groups B, BS, and CS-LS, and very little overlap with that for Group C.

\section{DISCUSSION}

The principal result of the Marrazo et al. study was replicated in this experiment. Use of a $5-\mathrm{sec}$ CS-contingent shock during avoidance-response prevention significantly facilitated avoidance extinction. There was even some tendency for Group CS-LS animals to extinguish more rapidly than those in Group B (nine nonresponding animals vs. five). By contrast, reinforcement of CS presentations with a .5 -sec shock during response prevention substantially increased the resistance to extinction of the avoidance response. On the average, extinction required more than twice as many trials for Group CS-BS than for Group C. Furthermore, there was no facilitation of extinction even when animals were exposed to .5 -sec shock alone (i.e., in the absence of CS) during response prevention. The key procedural difference between the two CS-contingent shock groups was the difference in shock duration. It seems reasonable, therefore, to ascribe the facilitation of extinction for Group CS-LS and for the equivalent group in the experiment by Marrazo et al. to the long duration of the shock. It was suggested in the introduction that such a lengthy shock may suppress active behavior and lead to freezing or immobility, which might then persist during extinction trials when the animal was free to make the avoidance response. This was not the case. Animals in Group CS-LS were extremely active both during response prevention and, whether they responded or not, during subsequent extinction. On early response-prevention trials, this activity during the CS-US interval was directed toward the partition, while the shock itself produced primarily jumping behavior. Later in the response-prevention series, anticipatory jumping and other activity directed toward the ceiling of the shuttlebox (e.g., standing on the hind legs) occurred during the CS-US interval. In extinction, noncrossing animals continued to manifest such behavior during the CS. While jumping behavior and other ceiling-directed activity were initially shock-induced, there was ample opportunity for their reinforcement through momentary shock termination or reduction in the amount of body surface in contact with the grid. Furthermore, animals were removed from the shuttlebox by way of the ceiling at the end of each response-prevention trial. Animals exposed to brief shock during response prevention were also active, but tended throughout to direct their activity more toward the door or other parts of the shock compartment than toward the ceiling. Only the three noncrossing animals in Groups BS and CS-BS manifested much ceiling-directed activity. On the other hand, animals in Group B were essentially passive or even motionless by the end of the response-prevention phase and, in the case of nonresponders, during extinction.

All of the data of the present experiment are consistent with the assignment of a prominent role to Pavlovian processes in the influence of response prevention on the extinction of an avoidance response. In the absence of reinforcement, $\mathrm{CS}$ presentations during response prevention led to the typically reported (e.g., Baum, 1970) marked reduction in the number of trials required to extinguish an avoidance response. When brief shock was made contingent upon presentation of the CS during response prevention, the added Pavlovian conditioning significantly enhanced the resistance to extinction of an avoidance response. This enhancement was clearly due to the CS-shock contingency and not merely to shock exposure, since Group CS-BS required significantly more trials to extinguish than Group BS. In fact, exposure to brief shock without the CS present failed to increase resistance to extinction as compared with an unblocked group. Thus, the study by Marrazo et al. should not be interpreted to rule out a significant contribution of Pavlovian processes to the influence of response prevention upon avoidance extinction. Rather it demonstrates that competing responses induced by a long-duration shock may mask or counteract the normal action of such processes.

\section{REFERENCES}

Baum, M. Extinction of avoidance responding through response prevention (flooding). Psychological Bulletin, 1970, 74, 276-284.

Bersh, P. J., \& Keltz, J. R. Pavlovian reconditioning and the recovery of avoidance behavior in rats after extinction with response prevention. Joumal of Comparative and physiological Psychology, 1971, 76, 262-266.

Bersh, P. J., \& Paynter, W. E. Pavlovian extinction in rats during avoidance response prevention. Journal of Comparative and Physiological Psy chology, 1972, 78, 255-259.

Coulter, X., Riccio, D. C., \& Page, H, A. Effects of blocking an instrumental avoidance response: Facilitated extinction but persistence of "fear". Journal of Comparative and Physiological Psy chology, 1969, 68, 377-381.

Marrazo, M. J., Riccio, D. C., \& Riley, J. Effects of Pavlovian conditioned stimulus-unconditioned stimulus pairings during avoidance response-prevention trials in rats. Journal of Comparative and Physiological Psychology, 1974, 86, 96-100.

Solom on, R. L., \& Turner, L. H. Discriminative classical conditioning in dogs paralyzed by curare can later control discriminative avoidance responses in the normal state Psychological Review, 1962, 69, 202-219.

Trapold, M. A., \& Overmeier, J. B. The second learning process in instrumental leaming. In $A, H$. Black and W, F. Prokasy (Eds.), Classical conditioning II: Current theory and research. New York: Appleton-Century-Crofts, 1972, 427-452.

(Received for publication August 30, 1974; revision received December $10,1974$. ) 